\title{
ウンカ疫病菌（Erynia delphacis）に対する殺菌剤の影響
}

\author{
松井 武 彦 \\ 茨城県農業総合センター生物工学研究所
}

\begin{abstract}
Effects of Fungicides on Erynia delphacis Hori (Entomophthorales: Entomophthorceae). Takehiko Matsui (Plant Biotechnology Institute, Ibaraki Agricultural Center, Iwama, Ibaraki 319-0292, Japan). Jpn. J. Appl. Entomol. 43: 1-5 (1999)

Abstract: The effects of ten major fungicides commonly used in paddy fields to control hyphal growth and spore germination of Erynia delphacis were examined. All fungicides inhibited both hyphal growth and spore germination of the fungus on the medium. Isoprothiolane inhibited hyphal growth and secondary spore formation even at low concentrations. Spraying isoprothiolane directly onto the green rice leafhopper (Neophotettix cincticeps) inhibited fungal growth, but spraying the fungicide onto rice plants, did not inhibit fungal growth. When the fungicide was sprayed on paddy fields, the population of diseased insects decreased. However, the population of the green rice leafhopper increased.
\end{abstract}

Key words: Entomogenous fungus, Erynia delphacis, Nephotettix cincticeps, green rice leafhopper, fungicides

緒 言

ウンカ・ヨコバイ類は吸汁害による減収とウイルス病の 媒介者として水稲の重要な害虫であることから，毎年防除 スケジュールに組み込まれている．秋期に入ると，水田の ウンカ・ヨコバイの個体群に対してウンカ度病菌 (Erynia delphacis） が自然発生し，これらの個体群の密度を抑制し ている（島津, 1976; 李, 1984; Holdom et al., 1989). 方, いもち病, 紋枯病は, 水稲の重要病害として殺菌剤に よる防除が毎年実施されている. 天敵微生物の人為的導入, あるいは自然発生を助長させるなどの方法によって害虫類 を制御しようとする場合, 天敵微生物に対する殺菌剤の影 響を明らかにして括く必要がある。西東 $(1988,1994)$ 打 よび西東・藪田（1996）は施設栽培に拈けるVerticillium lecanii に対する各種殺菌剤の影響について報告してい る. 水田に用いられた微生物防除法では Metarhizium anisopliae, Beauveria bassiana, Hirsutella citriformis (森 本, 1954; Rombach et al., 1986a, b) 等の実施例がある. しかし，水田での殺菌剂散布が天敵微生物の自然発生に拉 よぼす影響についての報告はない，本報告では水田での殺 菌剤散布がッマグロヨコバイ個体群に打ける E. delphacis の発生にどのような影響を与えているのかについて，室内 実験と圃場実験により調査し，2,3 の知見を得たので報告 する.

本試験にあたり, 農業研究センター水田虫害研究室前室 長岡田斉夫博士 (現生研機構), 同室長平井一夫博士には 立案，実施にあたり助言と便宜をはかっていただいた。東
京農工大大学院農学研究科野瀬友利氏（現東京都庁）には 培地の調整をしていただいた．東北大学農学部教授羽柴輝 良博士, 茨城県生物工学研究所成澤才彦博士には論文の校 閲をしていただいた．深く感謝申し上げる.

\section{材料特よび方法}

\section{1. 殺菌剤添加培地上での Erynia delphacis の生育調査}

供試した Erynia delphacis は農業研究センター谷和原地 区水田のッマグロヨコバイ成虫から分離した NED 1 株で ある。供試した薬剤は，isoprothiolane（40\%乳剤）， EDDP (30\%乳剂), IBP (48\%乳剂), fultoranil (25\%水 和剤), mepronil (75\%水和剤), pencycron ( $25 \%$ 水和剤), fthalide $(50 \%$ 水和剂), tricyclazole $(75 \%$ 水和剂), kasugamycin (2.3\%液剂)， validamycin (3.0\%液剂) の 10 種類であり, 培地中の濃度が各薬剤の通常使用濃度 (Table 1)，㧊よびその 5 倍量，1/5 倍量の 3 段階になるよ らにした. SDY 培地（ペプトン $10 \mathrm{~g}$, 酵母エキス $10 \mathrm{~g}$,ブ ドウ糖 $20 \mathrm{~g}$, 寒天 $15 \mathrm{~g}$, 蒸留水 $1,000 \mathrm{ml})$ をオートクレー ブ隇菌後, 培地が固化する直前に各設定濃度になるように 薬剤をそれぞれ混和し, 直径 $9 \mathrm{~cm}$ のシャーレに分注し, 平板培地を作成した。作成した培地上に，根本培地（ぺプ トン $10 \mathrm{~g}$, ブドウ糖 $20 \mathrm{~g}$, 寒天 $15 \mathrm{~g}$, 粉末卵黄 $43 \mathrm{~g}$, 蒸留 水 $1,000 \mathrm{ml}$ ) で 1 週間増殖させた E. delphacis をコルク ボーラーで直径 $4 \mathrm{~mm}$ に打ち抜さ, 1 シャーレあたり 4 個 ずつ静置した. 調査は 3 日後に菌叢の直径を測定すること により行い,薬㶡無添加の SDY 培地を対照として用いた。 一方, シャーレの蓋の内側ガラス面に培地ごと打ち抜いた 
Table 1. Conventional concentration of fungicides commonly used in paddy fields

\begin{tabular}{lclc}
\hline \multicolumn{1}{c}{ Fungicide } & $\begin{array}{c}\text { Ingredient } \\
(\%)\end{array}$ & \multicolumn{1}{c}{ Formulation } & Conventional concentration \\
\hline ppm) & emulsifiable concentrate & 400 \\
Isoprothiolane & 40 & emulsifiable concentrate & 300 \\
EDDP & 30 & emulsifiable concentrate & 480 \\
IBP & 48 & wettable powder & 250 \\
Fultoranil & 25 & wettable powder & 600 \\
Mepronil & 75 & wettable powder & 143 \\
Pencycron & 25 & wettable powder & 400 \\
Fthalide & 50 & wettable powder & 188 \\
Tricyclazole & 75 & liquid formulation & 23 \\
Kasugamycin & 2.3 & liquid formulation & 40 \\
Validamycin & 3.0 & &
\end{tabular}

菌叢をとのまま張り付け，胞子を各培地上に落下させ，2 日後の胞子の状態を観察した. 各試験は 3 反復行った.

\section{2. 虫体への殺菌剤散布が E. delphacis の発生に与える 影響}

虫体に付着した殺菌剤が E. delphacis の感染，あるい は感染後の発病に対してどのような影響を与えるかを知る ため, ッマグロヨコバイの成虫に isoprothiolane 乳剤を散 布し, 24 時間後に $E$. delphacis を 24 時間接種した. また， E. delphacis を 1 日前（24 時間）飞接種した感染虫に isoprothiolane 乳剤 1,000 倍液を散布し，体表面が乾燥し た後イネ苗の入った上記ガラスチューブに移し，発病を観 察した，対照として，健全虫に薬剤の及を散布した区，薬 剤無散布で E. delphacis 接種のみの区，薬剤，菌両者無 処理の区を設定した.

虫体への薬剤散布は以下の方法で行った。すなわち, $35 \times 32 \times 37 \mathrm{~cm}$ の透明アクリル樹脂の容器に成虫を放飼 し, 供試薬剤の 1,000 倍液を $5 \mathrm{ml}$ 噴霧した後, 容器の壁 面の薬液を拭い，餌のイネ苗を入れ，虫体の乾くまで 24 時間放置した. E. delphacis の虫体への接種は以下の方法 で行った.すなわち，ガラスシャーレの素寒天プレート上 に根本培地で培養した菌叢を移植し, 移植した素寒天プ レートをイネ幼苗の入った直径 $9 \mathrm{~cm}$, 高さ $20 \mathrm{~cm}$ のガラ ス容器の上面に反転させてのせ, 胞子を落下させた。ッマ グロヨコバイの発病調査は接種 4 日後就よび 6 日後に行っ た. 実験は 1 区 9 頭から 16 頭を供試し， 3 反復行った.

3. イネ株への殺菌剤散布が E. delphacis の発生に与え る影響

イネ株上に散布した殺菌剤が E. delphacis の発生にど のよらな影響を与えるかを知るため，1/5,000 a ポットに 栽培した登熟期のイネに isoprothiolane 乳剂 1,000 倍夜を 1 株当たり $5 \mathrm{ml}$ 噴霧した. 散布 24 時間後に，テトロンゴー スの網で頂部を塞いだ直径 $16 \mathrm{~cm}$, 高さ $70 \mathrm{~cm}$ の塩化ビ ニール製の円筒で殺菌剤を散布したイネを覆い，ッマグロ ヨコバイ成虫を放飼した。.ツマグロヨコバイ放飼後に $E$. delphacis の胞子を後述の方法で 24 時間接種し， 6 日後に 発病を調査した．接種は菌叢を素寒天上に移植したプラス チックシャーレを，円筒の頂部のテトロンゴース網と両面 テープで固定し, 胞子を落下させる方法で行った. 実験は, この他に薬剤を散布したイネに，前もって E. delphacis を接種した感染虫を放飼した区，薬剤無散布で E. delphacis 接種のみの区, 薬剤, 菌両者無接種区の 3 区を設定し て，1区13 頭から 18 頭を供試し，2反復行った。

\section{4. 殺菌剤の圃場散布が E. delphacis の発生に与える 影響}

Isoprothiolane 乳剤を水田に散布し，ッマグロヨコバイ の個体群密度と E. delphacis の自然発生との関係を調査 した. 1990 年 9 月 11 日に水戸の茨城県農業試験場圃場（品 種；日本晴）に括いて動力噴霧器で 1,000 倍液を $150 \mathrm{l} / 10 \mathrm{a}$ 散布した．実験は 1 区 $2 \mathrm{a}, 1$ 区制で行った.

ッマグロヨコバイの発生密度調査はすくい取り法で, 雨 天を避け扮扮む称 7 日間隔で行った。直径 $36 \mathrm{~cm}$ の捕虫 網を用い， 5 往復（10 回）を 1 単位として採集されたツマ グロヨコバイの個体数を計測した。な拉，すくい取りは 3 反復行った. E. delphacis の発病調査はすくい取り調査後 のツマグロヨコバイを加湿した黒色濾紙の入ったポリェチ レン袋に生きたまま入れて,虫体からの白色の菌系の伸長, 胞子の形成を観察することで行った．発病の観察は採集 1 日後から 7 日後まで行い, その間の病死蜘の累積値を採 集日の発病虫数とした。

\section{結果拈よび考察}

\section{1. 殺菌剤添加培地における E. delphacis の生育}

イネの主要病害であるいるち病および紋枯病防除用の供 試 10 薬剤すべてが，それらを添加した培地上に拁ける $E$. delphacis の菌系の伸長を抑制した。供試薬剤中, isoprothiolane 乳剤では, 通常使用量の $1 / 5$ 倍量となるよ ら培地に添加した場合でも菌系の伸長は認められなかっ たＩBP の添加では低濃度でわずかに伸長が認められ， 
通常施用濃度 (188 ppm) の tricyclazole の添加の場合で は, 菌糸の伸長は無処理に比べ $15 \%$ であった。一方, kasugamycin の通常施用濃度 $(23 \mathrm{ppm})$ の添加では, 菌 杀の伸長は無処理の $72.3 \%$ と抑制が最も小さかった (Table 2).

昆虫疫病菌は 1 次胞子が発芽すると, 直接 2 次胞子を形 成する場合と，発芽管を伸長させる場合がある.SDY 培 地上に落下させた 1 次胞子から 2 次胞子の形成は, 無処理 区では94\%を示したが，発芽管の伸長は認められなかっ た. Isoprothiolane, IBP, EDDP, mepronil 㧊よび fultoanil の 5 薬剂をそれぞれ添加した培地では, 全ての濃度で 2 次 胞子の形成は認められなかった. Kasugamycin, validamycin を $1 / 5$ 濃度になるように添加した培地では 2 次胞子の 形成が認められた. Pencycron, fthalide あるいは tricyclazole を通常施用濃度と $1 / 5$ 濃度になるよらに添加した培 地では 2 次胞子の形成が認められ, pencycron あるいは fthalide を添加した培地では, 1 次胞子からの発芽管の伸 長が認められた。
以上のことから, 通常の $1 / 5$ 濃度で E. delphacis に対 し,もっとも強い抑制効果を示した薬羭は isoprothiolane であり, 次に IBP であった.

以降の実験では E. delphacis と殺菌剤の培地上での試 験結果から, 菌系の伸長, 胞子の形成にもっとも影響の大 きかった isoprothiolaneを用いた。

\section{2. 虫体への殺菌昘散布と E. delphacis の発生}

薬剂無散布で E. delphacis 接種区のツマグロヨコバイ の 4 日後の死亡率は $96.3 \%$, 胞子形成虫率は $80.5 \%$ であ ったのに対して, isoprothiolane 乳剂をツマグロヨコバイ の虫体に散布後，E. delphacis を接種した区では，4 日後 の死亡率が $45.9 \%$, 胞子形成虫率が 3.3\%であった．しか し, この区は接種の 6 日後に死亡率 $100 \%$, 胞子形成虫率 61.5\%となった. Isoprothiolane 乳阂の散布は E. delphacis によるッマグロヨコバイの発病率の減少, 発病の遅延を引 き起こした（Table 3).E. delphacis 無接種で薬阂無散布 区の死亡率は 4 日後 $3.3 \% ， 6$ 日後 $10 \%$ であったのに対し て, isoprothiolane 乳剈だけ散布した区では 4 日後 $12 \%$,

Table 2. Effects of fungicides on hyphal growth and secondary conidial formation of Erynia delphacis

\begin{tabular}{|c|c|c|c|c|c|c|}
\hline \multirow{3}{*}{ Fungicide } & \multicolumn{3}{|c|}{ Hyphal growth $(\%)^{a}$} & \multicolumn{3}{|c|}{ Secondary conidial formation $(\%)^{b}$} \\
\hline & \multicolumn{3}{|c|}{ Dose } & \multicolumn{3}{|c|}{ Dose } \\
\hline & 0.2 times $^{c}$ & 1 time & 5 times & 0.2 times & 1 time & 5 times \\
\hline Isoprothiolane & 0 & 0 & 0 & 0 & 0 & 0 \\
\hline EDDP & 61.6 & 42.3 & 18.1 & 0 & 0 & 0 \\
\hline IBP & 2.3 & 0 & 0 & 0 & 0 & 0 \\
\hline Fultoranil & 44.7 & 42.7 & 24.6 & 0 & 0 & 0 \\
\hline Mepronil & 53.1 & 43.8 & 53.1 & 0 & 0 & 0 \\
\hline Pencycron & 73.6 & 50.8 & 56.7 & 28.7 & 22.3 & 0 \\
\hline Fthalide & 63.5 & 55.4 & 55.4 & 53.2 & 28.6 & 0 \\
\hline Tricyclazole & 73.8 & 15.0 & 0 & 99.0 & 44.6 & 0 \\
\hline Kasugamycin & 84.6 & 72.3 & 63.1 & 89.9 & 0 & 0 \\
\hline Validamycin & 68.7 & 56.9 & 48.5 & 64.8 & 0 & 0 \\
\hline
\end{tabular}

a Hyphal growth on medium with fungicide/hyphal growth on medium without fungicide.

b Number of empty spores/number of total spores on medium with fungicide

Number of empty spores/number of total spores on medium without fungicide .

c Standard concentration.

Table 3. Effects of isoprothiolane on mortality of Nephotettix cincticeps and Erynia delphacis when fungicide sprayed on insects

\begin{tabular}{|c|c|c|c|c|c|c|}
\hline \multicolumn{2}{|c|}{ Treatments } & \multirow{2}{*}{$\begin{array}{c}\text { No. of } \\
\text { tested insects }\end{array}$} & \multicolumn{2}{|c|}{4 days after treatments } & \multicolumn{2}{|c|}{6 days after treatments } \\
\hline E. delphacis & Isoprothiolane & & $\underset{(\%)}{\text { Mortality }}$ & $\begin{array}{l}\text { Rate of conidial } \\
\text { formation }(\%)\end{array}$ & $\begin{array}{l}\text { Mortality } \\
(\%)\end{array}$ & $\begin{array}{l}\text { Rate of conidial } \\
\text { formation }(\%)\end{array}$ \\
\hline+ & pretreatment $^{\mathrm{a}}$ & 29 & 45.9 & 3.3 & 100 & 61.5 \\
\hline pretreatment & + & 30 & 100 & 40 & - & - \\
\hline+ & - & 39 & 96.9 & 80.5 & 100 & 82.7 \\
\hline- & + & 29 & 12.0 & 0 & 58.5 & 0 \\
\hline- & - & 30 & 3.3 & 0 & 10.0 & 0 \\
\hline
\end{tabular}

a Pretreatment performed $24 \mathrm{~h}$ earlier. 
6 日後 58.5\%を示した. この結果は薬剤そのものが健全虫 に影響を与えていると考兄られる。一方，E. delphacis を 前もって接種し, 感染させた虫に isoprothiolane 乳剂を散 布すると，4 日後の死亡率は $100 \%$ であったが，すでに 2 日後には 73\%（22/30 頭）の高い死亡率を示した。これら 死亡個体の $23 \%$ （5/22 頭）から虫体表面上に菌叢の形成 が認められたが，菌叢の形成量は少なく，体表の一部分に 認められただけであった。

以上のことから, isoprothiolane 乳剤がッマグロヨコバ イの虫体に付着すると E. delphacis の感染が阻害され， 虫体表面上での菌叢の生育も抑制され, 胞子の形成量も少 なくなると考えられた。

\section{3. イネ株への殺菌剤散布と E. delphacis の発生}

ポット栽培のイネ株に isoprothiolane 乳剂を散布後, ツ マグロヨコバイを放飼し，E. delphacis をツマグロヨコバ イに接種した区と，薬剤無散布で $E$. delphacis を接種し た区との間で, E. delphacis の発生率に差は認められなか った。また，薬剤を散布し，E. delphacis の感染虫を放飼
した区に执いても胞子形成虫率が 100\%になり，発生は抑 制されなかった（Table 4).E. delphacis を接種した胞子 形成虫の体表面に形成された菌叢は虫体全体を覆い，肉眼 観察では薬剤散布区と無散布区で差異は認められなかっ た.このことから、イネ株に付着した isoprothiolane 乳剤 は E. delphacis によるッマグロヨコバイの発病を抑制し ないと考兄られた。

4. 殺菌剤の圃場散布とE. delphacis の発生

Isoprothiolane 乳剤を水田に散布し, ツマグロヨコバイ の密度と自然発生した E. delphacis による死亡率の消長 を無散布区と比較した。

固場に扣ける E. delphacis の発生は9月 3 日から観察 された．殺菌剤散布 7 日後に，散布区の E. delphacis の 発生率は無散布区に比べ低くなり，その後回復した。この ことから殺菌剤が E. delphacis の発生率に長期間は影響 を与えないことが考えられた。 しかし，ツマグロヨコバイ の密度は殺菌剤散布区で高い傾向が続いた（Fig. 1).

Table 4. Effect of isoprothiolane on mortality of Nephotettix cincticeps and Erynia delphacis when fungicide sprayed on rice plants

\begin{tabular}{|c|c|c|c|c|c|c|}
\hline \multicolumn{2}{|c|}{ Treatments } & \multirow{2}{*}{$\begin{array}{c}\text { No. of } \\
\text { tested insects }\end{array}$} & \multicolumn{2}{|c|}{4 days after treatments } & \multicolumn{2}{|c|}{6 days after treatments } \\
\hline E. delphacis & Isoprothiolane & & $\begin{array}{c}\text { Mortality } \\
(\%)\end{array}$ & $\begin{array}{l}\text { Rate of conidial } \\
\text { formation }(\%)\end{array}$ & $\begin{array}{c}\text { Mortality } \\
(\%)\end{array}$ & $\begin{array}{l}\text { Rate of conidia } \\
\text { formation }(\%)\end{array}$ \\
\hline+ & pretreatment $^{\mathbf{a}}$ & 32 & 72.0 & 53.1 & 90.8 & 87.9 \\
\hline pretreatment & pretreatment & 23 & 100 & 100 & - & - \\
\hline+ & - & 35 & 63.9 & 61.0 & 88.9 & 80.2 \\
\hline - & - & 28 & 0 & 0 & 0 & 0 \\
\hline
\end{tabular}

a Pretreatment performed $24 \mathrm{~h}$ earlier.

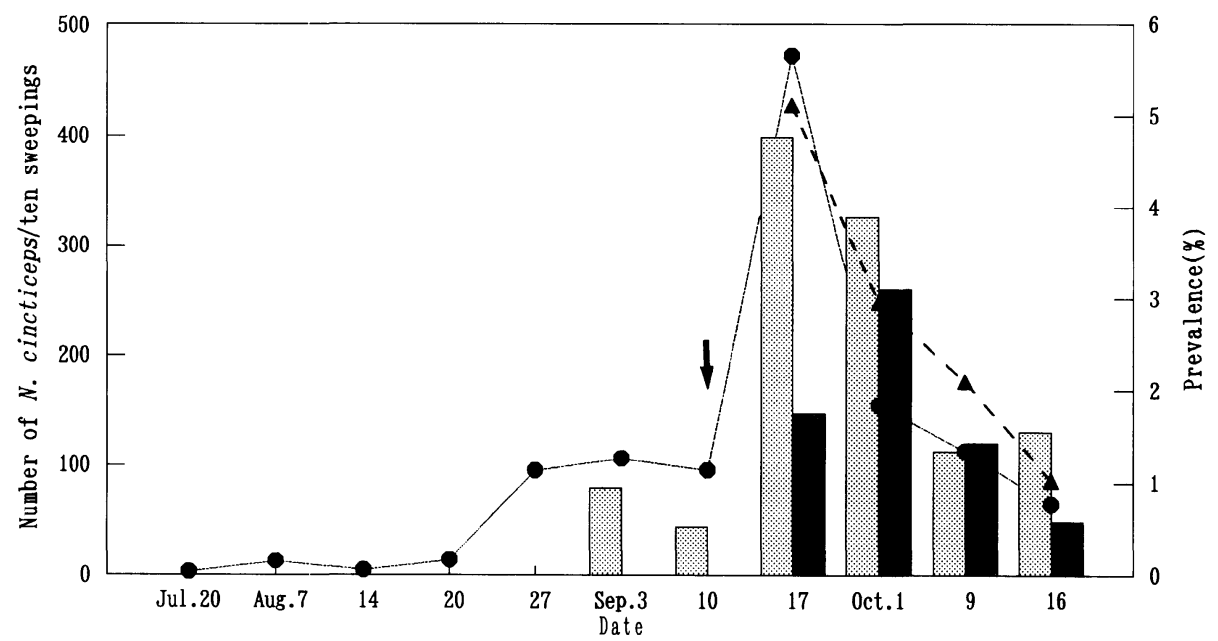

Fig. 1. Populations of $N$. cincticeps and prevalence of $E$. delphacis after spraying fungicide in paddy fields (1990). Number of $N$. cincticeps: $O$, control; $\Delta$, fungicide treatment. Prevalence: infected insects/number of $N$. cincticeps: 周, control; $\square$, fungicide treatment. $\downarrow$, Fungicide sprayed on field on 11 September. 
考

察

水田に拈ける殺菌剤の散布はイネ株に広範に付着するこ とを目的に行われるが，同時に，水田内に生息する昆虫類 の体表にも付着すると考光られる．E. delphacis はウン カ・ヨコバイ類に対して胞子によって感染することから, 殺 菌剂が胞子の形成を抑制し, 殺菌剂散布後の E. delphacis の発生率の低下が生じると考えた。

虫体に付着した isoprothiolane は 24 時間後の感染率を やや低下させる程度であったが，感染虫の発病を抑制した (Table 3). また, イネ株への isoprothiolane の付着は $E$. delphacis の発生にほとんど影響を示さなかった（Table 4). このことから，イネ株上に付着した胞子による感染は少な いことが推察された.

室内試験の散布結果, ならびに固場試験で E. delphacis の殺菌剤散布区の 7 日後の発生率が大きく減少した後回復 したこと（Fig. 1）からも，E. delphacis に対する殺菌剤 散布の影響が長期間持続しているとは考えられないが，秋 期の E. delphacis の流行期に殺菌剂の散布が行われると $E$. delphacis の発生が減少し, ウンカ・ヨコバイ類の密度抑 制を妨げることが示唆された。

西東・藪田（1996）はVerticillium lecanii 製剤に対する 殺菌剤の影響を試験しているが, 分生子懸濁液と殺菌剂溶 液を混和してハウス内で散布している.この分生子の発芽 に直接影響する方法でも，薬剤の種類によっては感染率を 低下させないことを報告している。 また, Stansly et al. （1990）はダイズの食葉性害虫の Nomuraea rileyi に対す る殺菌剤の散布が菌に対する影響が大きく, 直場の害虫密 度を增加させたと報告している．これらの結果は，対象と なる菌の種類, 殺菌剤の種類によって, それぞれ影響が異 なることを示していると考觉られる.

今回の試験は, 菌に対する抑制力の最も大さかった薬剤 の結果であり, 他の薬剤では本試験結果より影響が少ない ことが推察される.このことから水田に拈ける殺菌剤の使 用に大きな懸念は無いが, イネいもち病, 紋枯病などの防 除を目的とした殺菌剤使用にあたっては, 殺菌剤の種類, 散布時期を考慮しながら，E. delphacis によるウンカ・ヨ コバイ類の密度の抑制を図る必要があると考える.

$$
\text { 摘 要 }
$$

水田で使用されている主要な殺菌剤 10 種類をSDY 培 地に添加し, Erynia delphacis の菌系の伸長, 胞子の発芽 に対する影響を調査した。 その結果, 供試薬剤すべてが,
E. delphacis の生育を阻害したが, isoprothiolane の阻害 効果が最も大きかった。 Isoprothiolane を低濃度（80 ppm）で添加した培地に怙いては，菌系の伸長が認められ ず，2 次胞子の形成も認められなかった. ツマグロヨコバ イ成虫の虫体に isoprothiolane 乳剤を散布すると，E. delphacis の感染が阻害され，体表面に形成された菌叢も貧 弱なものであった.イネ株に isoprothiolane 乳剤を散布し た場合には E. delphacis の感染および虫体表面の菌叢の 形成に影響は認められなかった。

Isoprothiolane 乳剂を水田に散布した場合, E. delphacis によるッマグロヨコバイの発病率が無散布区より一時的に 低くなる傾向を示した．このことから，殺菌剤の E. delphacis の流行期の散布はツマグロヨコバイの密度抑制を 阻害する可能性があると考兄られた。

\section{引用 文 献}

Holdom, D. G., P. S. Taylor, R. J. Mackay-Wood, M. E. Ramos and R. S. Soper (1989) Field studies on rice planthoppers (Hom., Delphacidae) and their natural enemies in Indonesia. J. Appl. Entomol. 107: 118-129.

李 宏科（1984）褐稲䖽寄生菌一虫雷菌的初歩研究. 昆虫天敵 6: $132-135$.

森本徳右衛門（1954）黑賟病菌によるクロカメムシの防除. 植 物防疫 8: 395-397.

Rombach, M. C., R. M. Aguda, B. M. Shepard and D. W. Roberts (1986a) Entomopathogenic fungi (Deuteromycotina) in the control of the black bug of rice, Scotinophara coarctata (Hemiptera; Pentatomidae) J. Invertebr. Pathol. 48: 174179.

Rombach, M. C., R. M. Aguda, B. M. Shepard and D. W. Roberts (1986b) Infection of rice brown planthopper, Nilaparvata lugens (Homoptera: Delphacidae), by field application of entomopathogenic hyphomycetes (Deuteromycotina). Environ. Entomol. 15: 1070-1073.

西東 力 (1988) Verticillium lecanii 製剤によるワタアブラムシ の防除と農薬の影響. 応動昆 32: 224-227.

西東 力 (1994) 施設害虫の微生物的防除. 植物防疫 48: 465-468.

西東 力・藪田実男 (1996) Verticillium lecanii の感染および病 死体上の菌系発育に対する各種殺菌剤の影響. 応動昆 40: 71-76.

島津光明（1976） トビイロウンカから分離した Entomophthora delphacis について. 応動屁 20: 144-150.

Stansly, P. A., G. Jacinto and M. Orellana (1990) Field manipulation of Nomuraea rileyi (Moniliales: Moniliaceae): effects of soybean defoliators in costal Ecuador. J. Econ. Entomol. 83: 2193-2195. 